\title{
INSPEKSI USABILITAS PADA LOCOMOTION TIGA APLIKASI REALITAS VIRTUAL BERBASIS CARDBOARD
}

\section{Usability Inspection of Locomotion on Three Cardboard Based Virtual Reality Applications}

\author{
AUZI ASFARIAN ${ }^{1} *$, HENGKY RACHMADHANI $^{1}$, FIRMAN ARDIANSYAH $^{1}$
}

\begin{abstract}
Abstrak
Realitas virtual memerlukan mekanisme interaksi yang menggerakkan pengguna di dunia (locomotion). Hingga saat ini sudah banyak aplikasi realitas virtual yang dikembangkan, seperti pada bidang permainan, kesehatan, dan navigasi. Penelitian ini berfokus menemukan masalah usabilitas locomotion pada aplikasi realitas virtual. Aspek tersebut dievaluasi dengan beberapa locomotion yang berbeda terhadap tiga aplikasi permainan. Analisis ini dilakukan untuk mendapatkan ringkasan informasi berupa locomotion yang menjadi masalah pada ketiga aplikasi realitas virtual. Hasil penelitian menyatakan bahwa masing-masing responden memiliki perbedaan kriteria pergerakan sistem yang efektif. Locomotion dengan tingkat kesulitan pergerakan yang berbeda akan berpengaruh pada masalah usabilitas dan memiliki efek samping yang berbeda. Locomotion movement 1:1 memiliki nilai modus tingkat ketidaknyamanan yang tinggi dengan skor 3, pengguna merasa sakit dan mengalami efek samping. Locomotion rail movement dan head-tracking movement memiliki tingkat kenyamanan yang tinggi sehingga pengguna tidak merasa sakit dan tidak mengalami efek samping.
\end{abstract}

Kata Kunci: Cardboard, interaksi, locomotion, realitas virtual, usabilitas

\begin{abstract}
Virtual reality needs an interaction mechanism to move the user in a virtual world while the user stays in an area. This mecanishm is called locomotion. Cardboard is the commonly used head-mounted display technology. Until now there are many virtual reality applications developed, such as games, health, and navigation. This research focuses on finding locomotion usability problem on virtual reality applications based on three VR game applications. An analysis is conducted to obtain a summary about locomotion that matters on those applications. Result shows that each respondent has different criteria of the effective movement system. Locomotion with different level of difficulty will affect usability and has a unique side effect. Locomotion movement 1:1 has a high level of discomfort with a mode value of 3, users got sickness and experienced after-effect. Locomotion rail movement and head tracking movement have high level of comfort; users do not get sick and do not suffer aftereffect.
\end{abstract}

Keywords: Cardboard, interaction, locomotion, usability, virtual reality

\section{PENDAHULUAN}

Realitas virtual (virtual reality) dengan menggunakan Head-Mounted Display (HMD) mengalami peningkatan dalam beberapa tahun terakhir (Asfarian dan Ardiansyah 2012). HMD untuk realitas virtual pada umumnya memiliki layar stereo berdampingan untuk menciptakan kesan ruang tiga dimensi. HMD juga dilengkapi dengan sensor gerak untuk mengestimasi pose dan menjejak pergerakan kepala pengguna. Informasi gerakan tersebut akan digunakan untuk menyesuaikan adegan yang dibangkitkan pada layar, menciptakan kesan seolah pengguna benar-benar berada di dalam dunia virtual.

Walaupun perangkat HMD high-end seperti Oculus Rift, HTC Vive, dan Play Station masih dijual dengan harga tinggi, telah muncul perangkat HMD yang terjangkau dan dapat

${ }^{1}$ Departemen Ilmu Komputer, FMIPA, Institut Pertanian Bogor.

*Penulis Korespondensi: Tel/Faks: 0251-8625584; Surel: asfarian@apps.ipb.ac.id 
diperoleh dengan mudah (Amer dan Peralez 2014). Salah satu perangkat tersebut adalah Google Cardboard (Smus et al. 2014) yang diperkenalkan pada tahun 2014. Cardboard dapat dibuat dengan biaya kurang dari seratus ribu rupiah dan dapat diakses oleh masyarakat Indonesia melalui toko daring. Perangkat ini berupa kerangka yang terbuat dari kardus. Agar dapat berfungsi sebagai HMD, diperlukan sebuah ponsel pintar yang memiliki sensor gerak. Beberapa variasi dibuat dari bahan plastik agar lebih tahan lama.

Google menyediakan perangkat pengembangan perangkat lunak untuk pengembangkan aplikasi yang menggunakan Cardboard. Hal ini menyebabkan jumlah aplikasi realitas virtual pada platform Android semakin bertambah. Penelitian-penelitian sebelumnya telah menggunakan Cardboard untuk membuat aplikasi di bidang kebudayaan (Fabola et al. 2015), rehabilitasi kesehatan (Bonfanti et al. 2015), dan navigasi (Powell et al. 2016). Akan tetapi, hingga saat ini masih sedikit penelitian yang secara spesifik membahas masalah usabilitas pada aplikasi realitas virtual dengan Carboard. Pada penelitian sebelumnya, Asfarian dan Salim (2019) telah mencoba melakukan inspeksi usabilitas terhadap tiga aplikasi realitas virtual menggunakan teknik evaluasi heuristik lingkungan virtual.

Penelitian ini akan meneliti usabilitas dari penerapan locomotion yang terdapat pada tiga aplikasi permainan yang menjadi objek penelitian Asfarian dan Salim (2019). Kriteria yang digunakan adalah kriteria efek samping dari Multi-criteria Assessment of Usability for Virtual Environments (MAUVE) (Stanney et al. 2002), yang terdiri atas comfort, sickness, dan after effects.

\section{TINJAUAN PUSTAKA}

\section{Realitas Virtual}

Relitas virtual pada awalnya dianggap merujuk pada teknologi, namun pengertian tersebut bergeser ke aspek pengalaman manusia. Steuer (1992) mendefinisikan realitas virtual sebagai: "lingkungan simulasi atau nyata yang memungkinkan pengguna merasa seolah-olah hadir dan memberi efek pada dunia virtual". Menurut LaValle (2017), terdapat empat komponen dasar dalam realitas virtual, di antaranya:

- Targeted behavior: pengguna memiliki pengalaman yang dirancang oleh pengembang, seperti terbang, berjalan, menjelajahi, menonton film, dan bersosialisasi dengan organisme

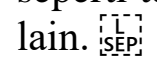

- Organism: organisme yang merepresentasikan diri pengguna sendiri, orang lain, bahkan

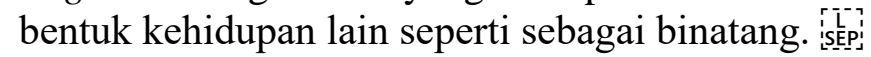

- Artificial sensory stimulation: indera manusia digantikan oleh stimulasi buatan.

- Awareness: kesadaran pengguna dapat dimasukan kedalam dunia virtual yang memberikan

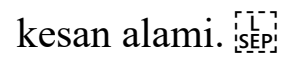

\section{Aplikasi Realitas Virtual}

Berdasarkan data yang dikumpulkan pada bulan Agustus 2017, perkembangan aplikasi realitas virtual terus menigkat. Pencarian pada Play Store menghasilkan sebanyak 250 aplikasi yang menggunakan Google Cardboard. Aplikasi yang memiliki versi lite tidak dihitung. Akan tetapi, aplikasi yang merupakan varian dihitung sebagai aplikasi berbeda, misalnya 'Lamper VR: Firefly Rescue' dengan 'Lamper VR: First Flight'. Berdasarkan jumlah aplikasi per kategori Play Store, terlihat bahwa aplikasi realitas virtual dengan kategori entertaintment mendominasi dari 250 aplikasi. Empat besar berikutnya berturut-turut adalah simulation, arcade, adventure, serta media and demo. Terlihat bahwa aplikasi realitas virtual lebih banyak digunakan pada aplikasi yang sifatnya hiburan. Walaupun realitas virtual memiliki potensi di bidang edukasi (Fabola et al. 2015) dan kesehatan (Bonfanti et al. 2015), jumlah kedua kategori tersebut lebih rendah. 


\section{Locomotion pada Aplikasi Realitas Virtual}

Menurut LaValle (2017) dunia virtual mencakup area yang jauh lebih luas daripada bagian dunia nyata yang ditelusuri. Zona yang relatif kecil dengan dunia virtual. Dalam hal ini, beberapa bentuk mekanisme interaksi diperlukan untuk menggerakkan pengguna di dunia virtual sementara ia tetap berada dalam area yang di telusuri di dunia nyata. Mekanisme interaksi yang menggerakkan pengguna dengan cara ini disebut locomotion. Seolah-olah pengguna menelusuri wahana virtual yang dikendalikan melalui dunia virtual. Terdapat sepuluh locomotion untuk lingkungan virtual (Roy 2015). Locomotion tersebut meliputi:

- Traditional Artificial Locomotion: menekan tombol pada controller atau keyboard untuk bergerak kearah tertentu.

- Movement 1:1: perpindahan tubuh fisik pengguna akan menggerakan tubuh virtual pengguna persis dengan jarak dan arah yang sama.

- Gain Movement System 1:X: perpindahan 1 meter dalam kehidupan nyata akan bergerak X jarak di dalam game.

- Teleportation: menghilang dari tempat pengguna saat ini dan muncul di tempat lain.

- Motion Sensor Movement: perpindahan controller dengan cara tertentu akan menggerakan tubuh virtual pengguna kedepan atau kearah tertentu.

- Treadmill: berjalan pada treadmill untuk mensimulasikan arah yang pengguna jalankan.

- Grabbing 3D Space: pengguna memindahkan dunia virtual bukan menggerakan tubuh fisik pengguna.

- Rail Movement: sebuah tindakan atau peristiwa pemicu tertentu menyebabkan tubuh virtual pengguna untuk bergerak di rute yang telah ditentukan untuk lokasi yang tetap.

- Thrust Movement: menekan tombol membuat pengguna bergerak menuju arah yang pengguna pilih berdasarkan kontrol yang terpisah.

- Other Unique Movement: beberapa aplikasi memiliki sistem gerakan tersendiri yang untuk membuat pengalaman khusus.

\section{Kriteria Usabilitas Lingkungan Virtual}

Multi-criteria Assessment of Usability for Virtual Environments (MAUVE) (Stanney et al. 2002) mengklasifikasikan pertimbangan antarmuka kedalam dua kategori kriteria kegunaan utama lingkungan virtual yaitu engagement dan side effect (efek samping). Identifikasi berdasarkan kedua kategori tersebut memungkinkan kategorisasi kriteria penggunaan spesifik terkait dengan permasalahan yang berkaitan dengan pengguna. Penelitian ini menggunakan kategori side-effect yang terdiri atas:

- Comfort: Kriteria utama untuk penerimaan lingkungan virtual adalah pengguna dapat berinteraksi dengan intuitif dan nyaman. Ketidaknyamanan saat berinteraksi dengan realitas virtual yang dirasakan dengan semua sensasi lain. Kenyamanan dan keamanan dalam menggunakan peralatan sangat penting untuk pengguna realitas virtual. Kriteria utama untuk penerimaan realitas virtual dalam bidang kedokteran adalah intuitif dan kenyamanan dari sebuah sistem. Membuat pengguna nyaman saat mengenakan perangkat layar atau berinteraksi dengan antarmuka adalah sangat penting karena ketidaknyamanan saat berinteraksi berpengaruh dengan semua sensasi lain.

- Sickness: Terdapat kelemahan dalam perkembangan teknologi realitas virtual yang dapat dirasakan oleh kehadiran gejala mabuk seperti yang terus mengganggu secara signifikan dari pengguna sistem. Kejanggalan sensorik yang cukup dapat mengakibatkan karena ketidaksesuaian antara rangsangan yang dirasakan dan diharapkan. Konflik sensorik seperti telah dilihat sebagai penyebab utama. Untuk mengatasi kejanggalan berpotensi sakitmerangsang, pengguna umumnya baik menarik diri dari interaksi dengan realitas virtual atau beradaptasi dengan lingkungan diatur kembali. Situasi terakhir ini menunjukkan pengguna harus beradaptasi kembali setelah kembali ke dunia nyata setelah interaksi dengan realitas virtual telah berhenti. Proses ini mungkin pada gilirannya, memicu gejala-gejala penyakit awal lagi sampai orang tersebut terbiasa dengan lingkungan normalnya. Timbul gejala 
penyakit seperti karenanya dapat ditemui baik selama dan setelah terpapar lingkungan virtual. Gejala penyakit umumnya dikategorikan sebagai mual, disorientasi, atau gangguan okulomotor.

- After Effect: Efek samping adalah efek yang diamati setelah peserta kembali ke dunia nyata setelah terpapar lingkungan virtual. Sementara cybersickness adalah efek samping fisiologis yang berkaitan dengan paparan realitas virtual. Kejanggalan sensorik yang melekat untuk berinteraksi dengan sistem realitas virtual dan perlu beradaptasi kembali ke dunia virtual dan dunia nyata, efek yang mungkin timbul dan berlama-lama pasca paparan mengganggu meliputi kepala berputar; ataxia postural; mengurangi koordinasi mata-tangan; dan visual atau gangguan vestibular. Efek samping ini dapat berlangsung dari beberapa menit atau jam ke hari dan bahkan bulan setelah paparan.

\section{METODE}

\section{Penentuan Aplikasi dan Locomotion}

Evaluasi locomotion ini dilakukan pada tiga aplikasi permainan realitas virtual (Gambar 1) yang digunakan oleh Asfarian dan Salim (2012). Ketiga aplikasi ditentukan dengan mempertimbangkan tugas dan locomotion yang bisa diujikan dengan alat yang tersedia oleh pengguna dalam lingkungan virtual. Penentuan ketiga aplikasi dengan locomotion berbeda berdasarkan aplikasi realitas virtual yang memiliki jumlah terbanyak pada PlayStore dengan menggunakan locomotion yang mudah tanpa alat bantu selain Cardboard. Deskripsi tugas dan locomotion yang terlibat dalam masing-masing aplikasi dapat dilihat pada Tabel 1.

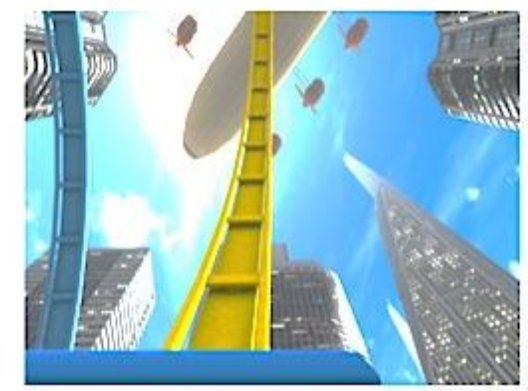

(a). Roller Coaster

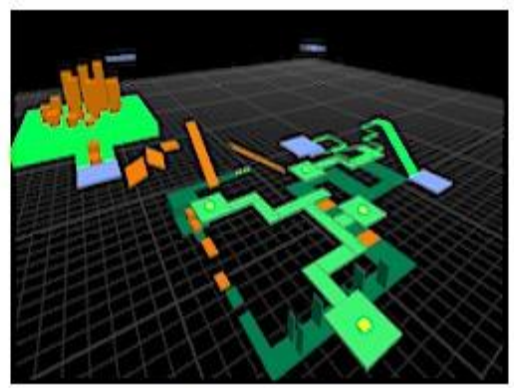

(b). Jump n Run

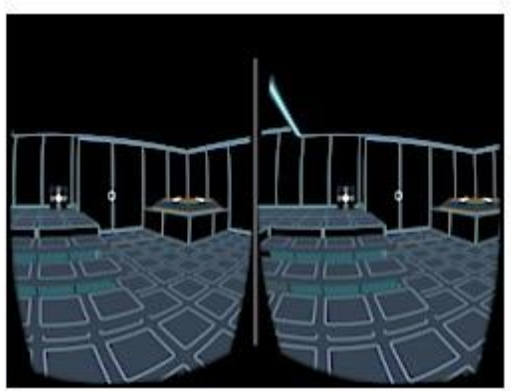

(c). Gravity Pull

Gambar 18 Tiga aplikasi permainan yang akan digunakan dalam pengujian ini.

Tabel 1 Tugas dan deskripsi locomotion pada ketiga permainan

\begin{tabular}{|c|c|c|}
\hline Aplikasi & Tugas & Locomotion \\
\hline $\begin{array}{l}\text { Roller } \\
\text { Coaster } \\
\text { Versi 2.0.7 }\end{array}$ & $\begin{array}{l}\text { Menelusuri rute rail } \\
\text { hingga mencapai finish. }\end{array}$ & $\begin{array}{l}\text { Locomotion Rail Movement: Pergerakan atau perpindahan bagi } \\
\text { pengguna untuk bergerak pada rute yang telah ditentukan untuk lokasi } \\
\text { yang tetap. }\end{array}$ \\
\hline $\begin{array}{l}\text { VR Jump n } \\
\text { Run } \\
\text { Versi } 1.08\end{array}$ & $\begin{array}{l}\text { Menelusuri jalan dan } \\
\text { melewati rintangan } \\
\text { hingga mencapai } \\
\text { checkpoint. }\end{array}$ & $\begin{array}{l}\text { Locomotion Head Tracking Movement: Kecepatan dan arah gerak } \\
\text { digerakan kepala. Rotasi dilakukan dengan penjejakan kepala. }\end{array}$ \\
\hline $\begin{array}{l}\text { Gravity Pull } \\
\text { Versi } 1.4\end{array}$ & $\begin{array}{l}\text { Menelusuri ruangan } \\
\text { yang berisi teka teki. }\end{array}$ & $\begin{array}{l}\text { Locomotion Movement 1:1: Perpindahan tubuh fisik pengguna akan } \\
\text { menggerakan tubuh virtual pengguna sesuai jarak dan arah yang sama. } \\
\text { Pengguna mensimulasikan kepala ketika bergerak. Gerak mundur } \\
\text { dimungkinkan dengan melihat ke atas. }\end{array}$ \\
\hline
\end{tabular}

\section{Praobservasi}

Sebelum dilakukan observasi penelitian, tahapan praobservasi dilakukan untuk mempersiapkan kelengkapan dan instrumen observasi yang meliputi: 
- Persiapan dokumen teknis observasi: Pada tahapan ini akan disiapkan perencanaan teknis pelaksanaan observasi yang akan dilakukan. Dokumen observasi ini akan menggunakan aplikasi realitas virtual dengan locomotion yang berbeda.

- Pembuatan kuesioner uji usabilitas: Pembuatan kuesioner uji usabilitas untuk responden yang sudah ditentukan yakni pengguna game realitas virtual yang belum pernah sama sekali atau jarang. Pembuatan kuesioner ini dilakukan sebagai bahan penilaian tingkat kekurangan dari tiga aplikasi realitas virtual tersebut. Kuesioner tersebut menggunakan konsep skala five-point Likert $(1=$ sangat tidak setuju, $2=$ tidak setuju, $3=$ netral, $4=$ setuju, $5=$ sangat setuju). Terdapat tiga dasar konsep pertanyaan yang akan menjadi acuan dalam pembuatan kuesioner. Konsep pertanyaan kuesioner tersebut berdasarkan tiga kriteria indikator rancangan sistem lingkungan virtual yang efektif (Stanney et al. 2002).

- Pemilihan responden: Tahapan ini dilakukan sebelum observasi untuk mendapatkan karakteristik literasi dan keterbiasaan responden dalam menggunakan aplikasi realitas virtual. Tahapan ini dilakukan pada responden mahasiswa Ilmu Komputer Institut Pertanian Bogor.

\section{Pelaksanaan Observasi}

Pada tahapan ini akan dilakukan observasi dalam pengumpulan data. Metode pengumpulan data yang akan digunakan dalam penelitian ini adalah dengan melakukan observasi pengamatan melalui analisis video (in vivo) serta melakukan pengisian kuesioner oleh kelima responden. Pelaksanaan observasi ini dilakukan kampus IPB selama dua minggu dengan responden dari mahasiswa Ilmu Komputer IPB yang belum pernah menggunakan aplikasi yang diujikan. Masing-masing responden menggunakan tiga aplikasi realitas virtual. Pemilihan responden didasarkan pada aspek literasi dan keterbiasaan mahasiswa menggunakan aplikasi realitas virtual yang diperoleh dari profiling responden.

Pengumpulan data melalui kuesioner akan dilakukan dengan pemberian kuesioner uji yang sudah dibuat pada tahap praobservasi. Tujuan dari pengisian kuesioner ini adalah agar penelitian dapat terfokus pada inti permasalahan pada interaksi permainan realitas virtual dan tidak terjadi perluasan topik. Sedangkan, pengumpulan data berupa rekaman video akan digunakan teknik in vivo. Pada teknik ini akan dilakukan pengumpulan data berupa perekaman layar ponsel, unggah jarak jauh, perekaman suara, perekaman log data dan penggunaan kamera perekam.

- Perekaman layar: Aktivitas perekaman ini dilakukan pada layar ponsel responden aplikasi realitas tertambah. Perekaman ini akan dilakukan dengan aplikasi perekam layar AZ Recorder. Tujuan dari perekaman ini adalah untuk mendukung analisis pada sebuah interaksi tingkat mikro dalam aplikasi pada perangkat (Brown et al. 2015).

- Unggah jarak jauh: Unggah jarak jauh digunakan agar memudahkan proses pengumpulan data perekam layar ponsel, diperlukan sebuah aktivitas unggah hasil rekaman tersebut. Aplikasi perekam AZ Sreen Recorder memberikan fitur penyimpanan otomatis yang akan terunggah langsung pada surel pengguna.

- Perekaman suara: Perekaman pada suara juga sangat dibutuhkan dalam analisis video. Hal ini karena suara dalam interaksi manusia dapat menggambarkan suasana yang dialami langsung oleh pengguna, baik merasa nyaman, kesulitan atau bahkan tidak suka dengan aplikasi tersebut.

- Penggunaan kamera: Penggunaan kamera untuk mendapatkan hasil rekaman secara keseluruhan, dibutuhkan perekaman dari lingkungan pengguna. Hal ini dilakukan agar mengetahui keadaan lingkungan sekitar pengguna dan agar tidak ada bagian interaksi yang terlewatkan pada saat penggunaan aplikasi realitas virtual tersebut (Gambar 2). 

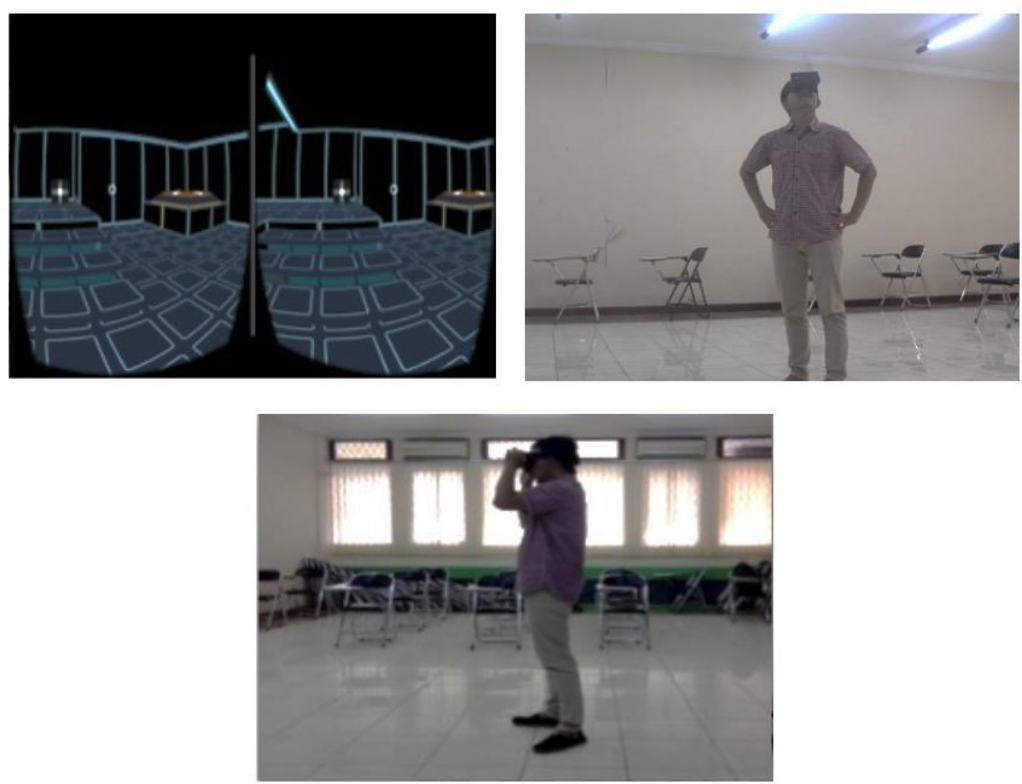

Analisis Data

Gambar 2 Contoh dokumentasi hasil perekaman sesi uji usabilitas.

Analisis data adalah tahapan terakhir pada penelitian ini yang dapat dilakukan setelah mendapatkan data dari tahapan observasi. Pada tahapan ini akan dilakukan proses analisis data berupa pereduksian video, pengkodean dan analisis interaksional. Reduksi data diperlukan untuk mempermudah penelitian dengan cara penyempitan durasi video dengan mengurangi rekaman yang tidak perlu seperti saat aktivitas-aktivitas pengguna di luar kepentingan penelitian. Pengkodean adalah pemeriksaan data secara detail dan menyeluruh yang akan dipahami. Pengkodean ini tidak hanya sebatas pemeriksaan video, log data dan lainnya tetapi juga hasil kuesioner penelitian yang sudah dikumpulkan. Analisis interaksional dilakukan untuk memahami makna interaksi melalui pembicaraan, gestur tubuh dan ekspresi dari pengguna saat menggunakan aplikasi realitas virtual. Pada analisis ini dilakukan proses transkripsi yaitu megubah seluruh interaksi di dalam video menjadi teks agar memudahkan dalam proses penelitian.

\section{Peralatan Penelitian}

Spesifikasi Ponsel Sony Experia Z dengan spesifikasi prosesor quad-core $1.5 \mathrm{GHz}$ Krait, memori 2 GB, layar 5 inci dengan resolusi 1980 x 1920 piksel, Android versi 5.1.1 serta perangkat Google Cardboard.

\section{HASIL DAN PEMBAHASAN}

\section{Praobservasi}

Pada tahap ini, kuesioner untuk mengukur respons peserta dibuat dalam bahasa Indonesia (Tabel 2). Terdapat lima belas pertanyaan yang dibagi dalam tiga kategori pertanyaan yang dijawab menggunakan skala likert. Selain itu, sebuah pertanyaan terbuka ditambahkan di setiap kategori pertanyaan untuk mendapatkan jawaban langsung dari pengguna.

\section{Hasil Kuesioner}

Hasil kuesioner kategori comfort dapat dilihat pada Tabel 3. Pada aplikasi Roller Coaster, sebagian besar responden merasa mudah dan nyaman selama penggunaan aplikasi serta tidak mengalami kelelahan fisik dan merasa sehat pada sendi pergerakan. Pada aplikasi Jump n Run, sebagian besar responden merasa tidak nyaman selama penggunaan dengan nilai modus sebesar 3. Pada aplikasi Gravity Pull, sebagian besar responden merasa tidak nyaman selama 
penggunaan aplikasi yang berupa responden merasa mengalami kelelahan fisik terutama pada mata.

Hasil kuesioner sickness dapat dilihat pada Tabel 4. Pada aplikasi Roller Coaster sebagian besar responden tidak mengalami kondisi disfungsi atau sakit selama penggunaan aplikasi dengan total nilai modus sebesar 2. Pada aplikasi Jump n Run, sebagian besar responden mengalami kondisi disfungsi atau sakit berupa mual dan sakit kepala selama penggunaan. Pada aplikasi Gravity Pull, hampir semua responden mengalami kondisi disfungsi atau sakit berupa mengalami kondisi berkeringat, kelelahan, mual dan sakit kepala yang menyebabkan ketidaknyamanan selama penggunaan aplikasi.

Hasil kuesioner kategori after effect dapat dilihat pada Tabel 5. Aplikasi Roller Coaster memiliki nilai total modus 1 yang artinya sebagian besar responden tidak mengalami efek samping pasca penggunaan aplikasi. Pada aplikasi Jump n Run, sebagian besar responden tidak mengalami efek samping dengan nilai total modus 2. Pada aplikasi Gravity Pull, semua responden mengalami efek samping berupa gejala kesulitan fokus, pusing, dan mual.

Tabel 2 Kuesioner yang digunakan untuk mengukur comfort, sickness, dan after effect

\begin{tabular}{l} 
No $\quad$ Pertanyaan \\
\hline Comfort \\
1 Apakah anda merasa terganggu untuk penggunaan aplikasi jangka panjang? \\
2 Apakah anda mengalami kelelahan fisik selama penggunaan aplikasi secara berkepanjangan? \\
3 Apakah anda menggalami kelelahan mata seperti menegang selama penggunaan aplikasi? \\
4 Apakah anda merasa tidak sehat pada sendi pergerakan selama penggunaan aplikasi? \\
5 Apakah anda merasa sulit dalam penggunaan perangkat virtual (Cardboard) pada aplikasi? \\
Sickness \\
6 Apakah anda berkeringat selama menggunakan aplikasi? \\
7 Apakah anda mengalami kelelahan selama menggunakan aplikasi? \\
8 Apakah anda mengalami mual selama menggunakan aplikasi? \\
9 Apakah anda mengalami sakit kepala selama menggunakan aplikasi? \\
10 Apakah anda mengalami gangguan selama penggunaan aplikasi? \\
After Effect \\
11 Apakah anda mengalami gejala kesulitan fokus dan penglihatan kabur setelah menggunakan aplikasi? \\
12 Apakah anda mengalami gejala pusing dan mual setelah menggunakan aplikasi? \\
13 Apakah anda mengalami vertigo (kehilangan orientasi tegak) setelah menggunakan aplikasi? \\
14 Apakah efek samping yang anda alami bertahan untuk waktu yang lama setelah penggunaan aplikasi? \\
15 Apakah anda tidak ingin menggunakan kembali aplikasi?
\end{tabular}

Tabel 3 Hasil jawaban responden pada pertanyaan kategori comfort

\begin{tabular}{|c|c|c|c|c|c|c|c|c|c|c|c|c|c|c|c|c|c|}
\hline \multirow[t]{3}{*}{ Pertanyaan } & \multicolumn{17}{|c|}{ Frekuensi pilihan skala yang dilakukan oleh responden } \\
\hline & \multicolumn{6}{|c|}{ Roller Coaster } & \multicolumn{5}{|c|}{ Jump n Run } & \multicolumn{6}{|c|}{ Gravity Pull } \\
\hline & 1 & 2 & 3 & 4 & 5 & Mo* & 1 & 23 & 34 & 5 & Mo & 1 & 2 & 3 & 4 & 5 & Mo \\
\hline $\begin{array}{l}\text { Apakah anda merasa terganggu untuk } \\
\text { penggunaan jangka panjang? }\end{array}$ & 1 & 4 & 0 & 0 & 0 & 2 & 0 & 22 & 21 & 0 & 3 & 0 & 0 & 3 & 2 & 0 & 3 \\
\hline $\begin{array}{l}\text { Apakah anda mengalami kelelahan fisik } \\
\text { selama penggunaan aplikasi secara } \\
\text { berkepanjangan? }\end{array}$ & 0 & 4 & 1 & 0 & 0 & 2 & 0 & 32 & 20 & 0 & 2 & 0 & 2 & 3 & 0 & 0 & 3 \\
\hline $\begin{array}{l}\text { Apakah anda menggalami kelelahan mata } \\
\text { seperti menegang selama penggunaan aplikasi? }\end{array}$ & 0 & 5 & 0 & 0 & 0 & 2 & 0 & 14 & 40 & 0 & 3 & 0 & 2 & 3 & 0 & 0 & 3 \\
\hline $\begin{array}{l}\text { Apakah anda merasa tidak sehat pada sendi } \\
\text { pergerakan selama penggunaan aplikasi? }\end{array}$ & 1 & 3 & 1 & 0 & 0 & 2 & 0 & 13 & $\begin{array}{ll}3 & 1\end{array}$ & 0 & 3 & 0 & 2 & 2 & 1 & 0 & 3 \\
\hline $\begin{array}{l}\text { Apakah anda merasa sulit dalam penggunaan } \\
\text { perangkat virtual (cardboard) pada aplikasi? }\end{array}$ & 2 & 3 & 0 & 0 & 0 & 2 & 0 & 02 & 23 & 0 & 4 & 0 & 0 & 1 & 4 & 0 & 4 \\
\hline $\begin{array}{l}\text { Apakah anda merasa terganggu untuk } \\
\text { penggunaan aplikasi jangka panjang? }\end{array}$ & 1 & 4 & 0 & 0 & 0 & 2 & 0 & 22 & $\begin{array}{ll}2 & 1\end{array}$ & 0 & 3 & 0 & 0 & 3 & 2 & 0 & 3 \\
\hline & & & & & & 2 & & & Moc & & 3 & & & & Mod & & 3 \\
\hline
\end{tabular}

*Catatan: Mo berarti modus, atau nilai yang paling sering muncul 
Tabel 4 Hasil jawaban responden pada pertanyaan kategori sickness

\begin{tabular}{|c|c|c|c|c|c|c|c|c|c|c|c|c|c|c|c|c|c|}
\hline \multirow[t]{3}{*}{ Pertanyaan } & \multicolumn{17}{|c|}{ Frekuensi pilihan skala yang dilakukan oleh responden } \\
\hline & \multicolumn{6}{|c|}{ Roller Coaster } & \multicolumn{5}{|c|}{ Jump n Run } & \multicolumn{6}{|c|}{ Gravity Pull } \\
\hline & 1 & 2 & 3 & 4 & 5 & Mo & 1 & 23 & 4 & 5 & Mo & 1 & 2 & 3 & 4 & 5 & Mo \\
\hline $\begin{array}{l}\text { Apakah anda berkeringat selama menggunakan } \\
\text { aplikasi? }\end{array}$ & 2 & 3 & 0 & 0 & 0 & 2 & 0 & 41 & 0 & 0 & 2 & 0 & 1 & 2 & 1 & 1 & 3 \\
\hline $\begin{array}{l}\text { Apakah anda mengalami kelelahan selama } \\
\text { menggunakan aplikasi? }\end{array}$ & 2 & 3 & 0 & 0 & 0 & 2 & 0 & 32 & 0 & 0 & 2 & 0 & 2 & 2 & 1 & 0 & 3 \\
\hline $\begin{array}{l}\text { Apakah anda mengalami mual selama } \\
\text { menggunakan aplikasi? }\end{array}$ & 2 & 3 & 0 & 0 & 0 & 2 & 1 & 22 & 0 & 0 & 3 & 0 & 1 & 4 & 0 & 0 & 3 \\
\hline $\begin{array}{l}\text { Apakah anda mengalami sakit kepala selama } \\
\text { menggunakan aplikasi? }\end{array}$ & 1 & 4 & 0 & 0 & 0 & 2 & 0 & 41 & 0 & 0 & 2 & 0 & 0 & 4 & 1 & 0 & 3 \\
\hline \multirow[t]{2}{*}{$\begin{array}{l}\text { Apakah anda mengalami gangguan selama } \\
\text { penggunaan aplikasi? }\end{array}$} & 4 & 1 & 0 & 0 & 0 & 1 & 0 & 32 & 0 & 0 & 2 & 0 & 0 & 2 & 3 & 0 & 4 \\
\hline & & & \multicolumn{3}{|c|}{ Modus } & 2 & & \multicolumn{3}{|c|}{ Modus } & 2 & & & \multicolumn{3}{|c|}{ Modus } & 3 \\
\hline
\end{tabular}

Tabel 5 Hasil jawaban responden pada pertanyaan kategori after effect

\begin{tabular}{|c|c|c|c|c|c|c|c|c|c|c|c|c|c|c|c|c|c|}
\hline \multirow[t]{3}{*}{ Pertanyaan } & \multicolumn{17}{|c|}{ Frekuensi pilihan skala yang dilakukan oleh responden } \\
\hline & \multicolumn{6}{|c|}{ Roller Coaster } & \multicolumn{5}{|c|}{ Jump n Run } & \multicolumn{6}{|c|}{ Gravity Pull } \\
\hline & 1 & 2 & 3 & 4 & 5 & Mo & 1 & 2 & 34 & 5 & Mo & 1 & 2 & 3 & 4 & 5 & Mo \\
\hline $\begin{array}{l}\text { Apakah anda mengalami gejala kesulitan fokus } \\
\text { dan penglihatan kabur setelah menggunakan } \\
\text { aplikasi? }\end{array}$ & 0 & 4 & 1 & 0 & 0 & 2 & 0 & 2 & 30 & 0 & 3 & 0 & 0 & 2 & 3 & 0 & 4 \\
\hline $\begin{array}{l}\text { Apakah anda mengalami gejala pusing dan } \\
\text { mual setelah menggunakan aplikasi? }\end{array}$ & 2 & 2 & 1 & 0 & 0 & 2 & 0 & 3 & 20 & 0 & 2 & 0 & 0 & 1 & 4 & 0 & 4 \\
\hline $\begin{array}{l}\text { Apakah anda mengalami vertigo (kehilangan } \\
\text { orientasi tegak) setelah menggunakan aplikasi? }\end{array}$ & 3 & 2 & 0 & 0 & 0 & 1 & 1 & 4 & $0 \quad 0$ & 0 & 2 & 0 & 1 & 2 & 1 & 1 & 3 \\
\hline $\begin{array}{l}\text { Apakah efek samping yang anda alami } \\
\text { bertahan untuk waktu yang lama setelah } \\
\text { penggunaan aplikasi? }\end{array}$ & 3 & 2 & 0 & 0 & 0 & 1 & 2 & 3 & $\begin{array}{ll}0 & 0\end{array}$ & 0 & 2 & 0 & 1 & 1 & 2 & 1 & 3 \\
\hline \multirow[t]{2}{*}{$\begin{array}{l}\text { Apakah anda tidak ingin menggunakan } \\
\text { kembali aplikasi? }\end{array}$} & 4 & 1 & 0 & 0 & 0 & 1 & 0 & 4 & 10 & 0 & 2 & 0 & 1 & 1 & 2 & 1 & 4 \\
\hline & & & \multicolumn{3}{|c|}{ Modus } & 1 & & & \multicolumn{2}{|c|}{ Modus } & 2 & & & \multicolumn{3}{|c|}{ Modus } & 4 \\
\hline
\end{tabular}

\section{Hasil Observasi}

Dalam penelitian ini teridentifikasi bahwa pengguna dalam lingkungan virtual memiliki kemampuan pada jangka waktu rata-rata kurang lebih 10 menit saat menggunakan HMD. Selain itu, respons pengguna pada masing-masing aplikasi realitas virtual sangat beragam (Gambar 3). Misalnya, locomotion pada aplikasi Jump n Run dan Gravity Pull memiliki pergerakan yang cukup kompleks. Responden memerlukan gerakan melompat di luar dari ekspektasi pengguna, gerakan kepala keatas dan kebawah dan pergerakan HMD 90 derajat. Berdasarkan hasil observasi diketahui aplikasi yang memiliki tingkat ketidaknyamanan yang tinggi yaitu aplikasi Roller Coaster, setelah itu Jump n Run dan Gravity Pull. Aplikasi yang memiliki efek disfungsi atau mengalami gejala sakit (sickness) tertinggi adalah Gravity Pull, diikuti oleh aplikasi Jump $\mathrm{n}$ Run dan Roller Coaster. Aplikasi yang memiliki efek samping tertinggi yaitu aplikasi Gravity Pull, setelah itu Jump n Run dan Roller Coaster.

Pada Gambar 3, terlihat nilai modus side effect terendah yakni Roller Coaster dan nilai modus tertinggi yakni Gravity Pull. Gravity Pull memiliki masalah pada kriteria ketidaknyamanan (comfort), timbul gejala sakit (sickness) dan mengalami akibat setelahnya (after effect) yang tinggi dibandingkan dengan kedua aplikasi realitas yang diujikan. Hal ini disebabkan aplikasi realitas virtual Gravity Pull memiliki locomotion yang tidak sederhana 
yaitu movement 1:1 artinya pergerakan di realitas virtual sama dengan dunia nyata. Selain itu jenis permainan realitas virtual labirin menyebabkan pengguna merasa pusing mengikuti perintah pada aplikasi ditambah dengan perintah pada aplikasi yang harus menggunakan tombol bantu untuk menggerakan balok pada labirin. Hal ini terlihat pada komentar ketika penggunaan aplikasi (Tabel 6).

Dengan demikian, berdasarkan hasil percobaan di atas, dapat disimpulkan bahwa walaupun berbiaya rendah, kualitas interaksi, terutama pada sisi locomotion, dari aplikasi yang menggunakan Google Cardboard masih bisa dibilang rendah. Selain interaksi yang sangat terbatas, kualitas perangkat dan implementasi dari interaksi di dalam permainan juga mempengaruhi kualitas interaksi yang dirasakan oleh pengguna. Oleh karena itu, penelitian ini mengusulkan bahwa diperlukannya standar atau petunjuk yang lebih rinci mengenai implementasi locomotion pada perangkat seperti Cardboard untuk meningkatkan kenyamanan pengguna saat menggunakan perangkat tersebut.

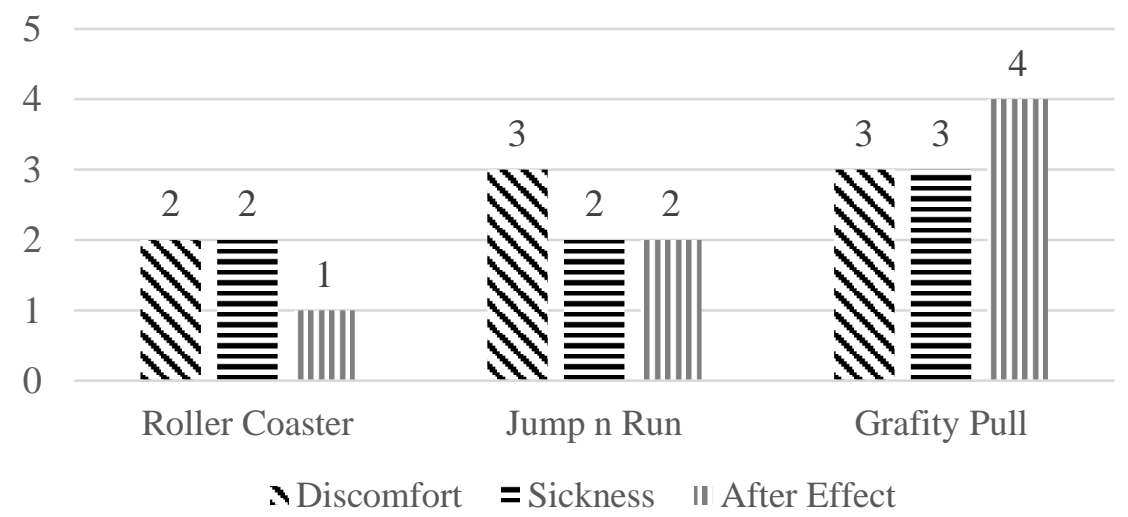

Gambar 3 Perbandingan nilai modus pada ketiga kategori.

Tabel 6 Jawaban pertanyaan terbuka yang diberikan pada responden

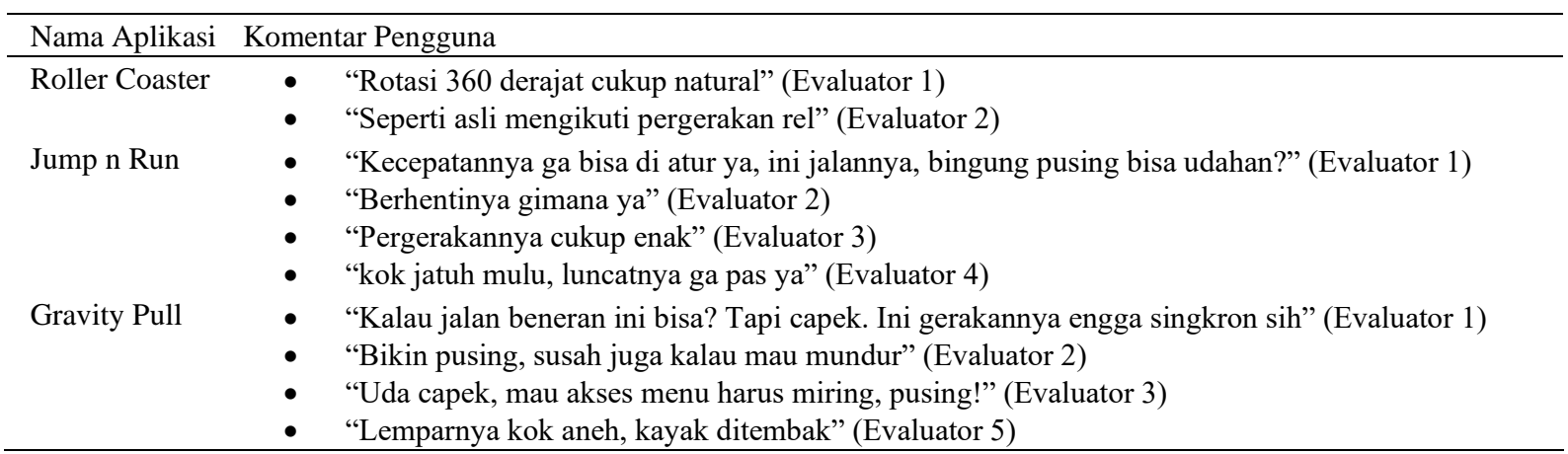

\section{Kelemahan}

Terdapat beberapa kelemahan pada penelitian yang dilakukan, yaitu (a) tidak semua locomotion dapat diuji, (b) sampel aplikasi yang digunakan terlalu sedikit, dan (c) tidak semua aspek diuji pada penelitian ini. Oleh karena itu, penelitian berikutnya disarankan untuk meningkatkan ketiga hal tersebut sehingga simpulan yang diambil dapat memiliki tingkat kepercayaan yang lebih tinggi.

\section{SIMPULAN}

Dari penelitian ini diperoleh bahwa locomotion yang diuji memiliki kekurangan dalam implementasi. Locomotion movement 1:1 memiliki nilai modus tingkat ketidaknyamanan yang tinggi dengan skor 3, pengguna merasa sakit dan mengalami efek samping. Locomotion rail 
movement dan head tracking movement memiliki tingkat kenyamanan yang tinggi sehingga pengguna tidak merasa sakit dan tidak mengalami efek samping. Dengan demikian, berdasarkan hasil percobaan dapat disimpulkan bahwa walaupun berbiaya rendah, kualitas interaksi, terutama pada sisi locomotion, dari aplikasi yang menggunakan Google Cardboard masih bisa dibilang rendah. Selain interaksi yang sangat terbatas, kualitas perangkat dan implementasi dari interaksi di dalam permainan juga mempengaruhi hasil

\section{DAFTAR PUSTAKA}

Amer A, Peralez P. 2014. Affordable altered perspectives: making augmented and virtual reality technology accessible. Di dalam: IEEE 2015 Global Humanitarian Technology Conference; 2015 8-11 Okt; Seattle, USA. hlm 603-608.

Asfarian A, Ardiansyah F. 2012. Rekayasa augmented reality mobile campus tour Institut Pertanian Bogor. Jurnal Ilmu Komputer dan Agri-Informatika. 1(1):1-6.

Asfarian A, Salim H. 2019. Inspeksi masalah usabilitas pada cardboard untuk permainan realitas virtual menggunakan teknik evaluasi heuristik lingkungan virtual. Jurnal Teknoinfo. 2019 Jan 15;13(1):22-8.

Bonfanti S, Gargantini A, Vitali A. 2015. A mobile application for the stereoacuity test. Di dalam: International Conference on Digital Human Modeling and Applications in Health, Safety, Ergonomics and Risk Management. hlm 315-326.

Brown B, McGregor M, Laurier E, editor. 2013. iPhone in vivo: Video Analysis of Mobile Device Use. Proceedings of the SIGCHI Conference on Human Factor in Computing Systems. Apr. 2013.

Fabola A, Miller A, Fawcett R. 2015. Exploring the past with Google Cardboard. Di dalam: IEEE Digital Heritage; Granada; 2015 Sep 28 - Okt 2. hlm 277-284.

LaValle SM. 2017. Virtual Reality. Cambridge (UK): Cambridge University Press.

Powell WA, Powell V, Brown P, Cook M, Uddin J. 2016. Getting around in Google Cardboard - exploring navigation preferences with low cost mobile VR. Proceedings of the 2016 IEEE 2nd Workshop on Everyday Virtual Reality. hlm 1-4.

Roy. 2016. Locomotion or moving. [Internet]. [diunduh 2016 Nov 1]; Tersedia pada: https://ignite-vr.com/blog/2016/09/24/locomotion-in-vr/.

Smus B, Plagemann C, Coz D. 2014. Cardboard: VR for Android [Internet]. Di dalam: Google I/O Conference. [diunduh 2016 Juni 25-26]. Tersedia pada: www.youtube.com/watch?v=DFog2gMnm44.

Stanney KM, Mollaghasemi M. Reeves L, Breaux R, Graeber DA. 2000. Usability engineering of virtual environments (VEs): identifying multiple criteria that drive effective VE system design. International Journal of Human-Computer Interaction. 58(3):447-481. doi:10.1016/S1071-5819(03)00015-6

Steuer J. 1992. Defining virtual reality: dimensions determining telepresence. Journal of Communication. 42(4): 73-93. 